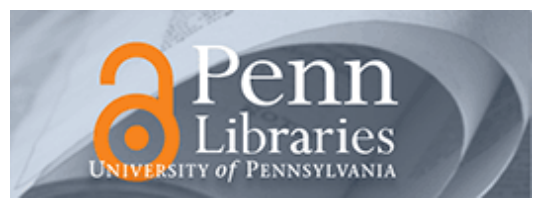

University of Pennsylvania

ScholarlyCommons

\title{
Do Family Privileges Bring Gender Equality? Instrumentalism and (De)Stereotyping of STEM Career Aspiration Among Chinese Adolescents
}

\author{
Ran Liu \\ University of Wisconsin-Madison, ran.liu@wisc.edu
}

Follow this and additional works at: https://repository.upenn.edu/education_inequality_workshop

\section{Recommended Citation}

Liu, Ran. 2019. "Do Family Privileges Bring Gender Equality? Instrumentalism and (De)Stereotyping of STEM Career Aspiration Among Chinese Adolescents." Penn Education and Inequality Working Papers, \#9. https://repository.upenn.edu/education_inequality_workshop/9

This is a pre-copyedited, author-produced version of an article accepted for publication in Social Forces following peer review. The version of record Liu, Ran. 2020. "Do Family Privileges Bring Gender Equality? Instrumentalism and (De) Stereotyping of STEM Career Aspiration Among Chinese Adolescents." Social Forces, 99(1):230-254 is available online at: https://doi.org/10.1093/sf/soz137.

This paper is posted at ScholarlyCommons. https://repository.upenn.edu/education_inequality_workshop/9 For more information, please contact repository@pobox.upenn.edu. 


\title{
Do Family Privileges Bring Gender Equality? Instrumentalism and (De)Stereotyping of STEM Career Aspiration Among Chinese Adolescents
}

\begin{abstract}
When studying the persistent underrepresentation of women in science, engineering, technology, and mathematics (STEM) fields across different countries, some evidence shows a paradox of affluence: gender differences in STEM aspirations and outcomes are found to be more pronounced in more developed, post-industrial countries and among students from more affluent families. The argument of "indulging gendered selves" provides an explanation: students in more affluent settings are less compelled to pursue lucrative STEM careers and more encouraged to indulge gendered passions as a form of self-expression. Extending this argument, this paper uses nationally representative data from China to examine the effect of family privileges on adolescents' STEM aspirations. Two distinct mechanisms are identified: instrumentalism, which considers the instrumental calculation of material security and economic returns in developing career aspirations, and (de)stereotyping, which considers whether family privileges cultivate or alleviate gender stereotypes. Findings show that less privileged girls such as ethnic minorities and those having rural hukou tend to have higher instrumental motivation to learn math, indicating an instrumentalism mechanism; on the other hand, girls with privileges such as higher parental education and more books at home enjoy more gender-egalitarian values, indicating a destereotyping mechanism. Moreover, Internet access at home as a privilege can foster gender stereotypes and decrease students' motivation to learn math, and the latter association is stronger for girls than boys. Results suggest the importance of distinguishing the instrumentalism and (de)stereotyping mechanisms and the need for educational programs to refute gender stereotypes.

\section{Keywords}

gender, STEM education, family

\section{Comments}

This is a pre-copyedited, author-produced version of an article accepted for publication in Social Forces following peer review. The version of record Liu, Ran. 2020. "Do Family Privileges Bring Gender Equality? Instrumentalism and (De) Stereotyping of STEM Career Aspiration Among Chinese Adolescents." Social Forces, 99(1):230-254 is available online at: https://doi.org/10.1093/sf/soz137.
\end{abstract}




\title{
Do Family Privileges Bring Gender Equality? Instrumentalism and (De)Stereotyping of STEM Career Aspiration Among Chinese Adolescents
}

\author{
Ran Liu
}

Key words: Gender, STEM Education, Family

\begin{abstract}
Acknowledgments
The author gratefully acknowledges support from the University of Pennsylvania's Benjamin Franklin Fellowship, and from the Student Research Grant of the Center for the Study of Contemporary China, University of Pennsylvania. The author would like to thank Emily Hannum, Hyunjoon Park, Natalie Young, Phoebe Ho, and Kennan Cepa for constructive comments. The author also thanks three anonymous reviewers whose comments helped to substantially improve the theoretical contribution of this manuscript. Correspondence to Ran Liu, University of Wisconsin-Madison, 235 Education Building, 1000 Bascom Mall, Madison, WI 53706, USA; email: ranliu@sas.upenn.edu.
\end{abstract}




\title{
Do Family Privileges Bring Gender Equality? Instrumentalism and (De)Stereotyping of STEM Career Aspirations Among Chinese Adolescents
}

\begin{abstract}
When studying the persistent underrepresentation of women in science, engineering, technology, and mathematics (STEM) fields across different countries, some evidence shows a paradox of affluence: gender differences in STEM aspirations and outcomes are found to be more pronounced in more developed, post-industrial countries and among students from more affluent families. The argument of "indulging gendered selves" provides an explanation: students in more affluent settings are less compelled to pursue lucrative STEM careers and more encouraged to indulge gendered passions as a form of self-expression. Extending this argument, this paper uses nationally representative data from China to examine the effect of family privileges on adolescents' STEM aspirations. Two distinct mechanisms are identified: instrumentalism, which considers the instrumental calculation of material security and economic returns in developing career aspirations, and (de)stereotyping, which considers whether family privileges cultivate or alleviate gender stereotypes. Findings show that less privileged girls such as ethnic minorities and those having rural hukou tend to have higher instrumental motivation to learn math, indicating an instrumentalism mechanism; on the other hand, girls with privileges such as higher parental education and more books at home enjoy more gender-egalitarian values, indicating a de-stereotyping mechanism. Moreover, Internet access at home as a privilege can foster gender stereotypes and decrease students' motivation to learn math, and the latter association is stronger for girls than boys. Results suggest the importance of distinguishing the instrumentalism and (de)stereotyping mechanisms and the need for educational programs to refute gender stereotypes.
\end{abstract}




\section{INTRODUCTION}

Despite the progress of gender equality in overall educational attainment in many countries during the past few decades, women are still underrepresented in science, engineering, technology, and mathematics (STEM) fields across the world (OECD 2015; National Science Foundation 2018; Riegle-Crumb, Moore, and Ramos-Wada 2011). More surprisingly, some evidence shows that gender inequality and segregation in students' fields of study and career aspirations is more pronounced in more developed, post-industrial countries (Charles and Bradley 2009; Charles and Grusky 2004; Charles 2017; Sikora and Pokropek 2012). Similarly, some scholars find that gender differences in STEM aspirations, attitudes, and performance are greater among students from more privileged families compared to their counterparts in less privileged families (Ma 2009; Charles et al. 2014; Perry et al. 2012; Penner and Paret 2008). These findings lead to a paradox of affluence: why cannot social and family affluence bring gender equality in STEM fields?

The argument of "indulging gendered selves" derived from comparative studies provides one possible explanation (Charles and Bradley 2009). It argues that students in more affluent settings are less pressured to pursue lucrative STEM careers. Instead, they are encouraged to indulge their passions for non-STEM pursuits that are believed to be more self-expressive and self-fulfilling. These passions, however, are in turn influenced by gendered values and stereotypes. Therefore, girls in more affluent settings are more attracted to non-STEM fields in the name of self-fulfillment and self-expression.

This paper argues that there are actually two mechanisms hidden behind the argument of "indulging gendered selves". The first mechanism is instrumentalism, which considers the instrumental calculation of material security and economic returns in developing career 
aspirations. The second mechanism is (de)stereotyping, which considers the possibility that more affluent settings cultivate or alleviate gender stereotypes. These two mechanisms may reinforce each other or work in different directions, and the effect of affluence depends on the tension between them. It is thus crucial to examine these two processes separately in order to better understand the effect of affluence on adolescents' career aspirations.

Previous studies using national level data rarely distinguish these two distinct mechanisms. Individual level data, on the other hand, provide opportunities to better discern these two mechanisms through examining individuals' motivation and stereotype endorsement. Using nationally representative data of middle school students in China, this study presents important evidence that family privileges work through these two distinct mechanisms in influencing boys' and girls' STEM aspirations. China provides a particularly interesting case for its vast socioeconomic inequality, persistent gender inequality and stereotypes, and highly standardized education system. Before developing the analytic models, I first briefly review current literature and the Chinese context.

\section{PRIVILEGES AND GENDER INEQUALITY IN STEM FIELDS}

\section{The Paradox of Affluence}

The conventional modernization theory believes that gender inequality in education and the labor market should decline as the modern competitive pressure increases and gender egalitarian values become institutionalized (Inglehart and Norris 2003; Baker and LeTendre 2005). However, while the gender gap in the overall educational attainment has reduced or even disappeared in many countries during the past few decades, the underrepresentation of women in STEM fields surprisingly persists (Xie and Shauman 2003; Riegle-Crumb, Moore, and RamosWada 2011; OECD 2015). Using country-level data on college graduates' majors, Charles and 
Bradley (2009) show universal underrepresentation of women in engineering programs in 44 countries. In the U.S., women in 2015 accounted for less than one-third of science and engineering employment (National Science Foundation 2018).

More surprisingly, evidence shows a "paradox of affluence" that some forms of gender segregation in education and the work force tend to be greater in more advanced, post-industrial countries. Charles and Bradley (2009) explores data from 44 countries, finding that gender segregation by fields of study is stronger in more developed countries. Sikora and Pokropek (2012) explores data from 50 countries, finding that gender gaps in adolescents' science selfconcept and career plans are both larger in more advanced, industrial countries than in developing and transforming countries. Charles et al. (2014) assess data from 53 countries and find that attitudinal gender gap towards math is larger in more affluent societies. In particular, attitudinal gender gaps are found to be very large in both advanced industrial countries and the "Asian Tiger groups" with highest Gross Domestic Product (GDP) and Human Development Index (HDI) scores. Further, using over-time data of 32 countries, Charles (2017) reveals that STEM aspirations become more gender differentiated as societal affluence grows within the same country.

The paradox of affluence exists not only at national level but also at individual level: larger gender gaps in STEM aspirations and attitudes have been found among students from more privileged families. For example, Charles et al. (2014) find a negative correlation between parental education and math aspiration among girls but not boys. This means higher parental education decreases girls' but not boys' interest in math-related fields, resulting in a larger gender gap among students with more educated parents. Similarly, Penner and Paret (2008) find that the male advantage among top math performers is most pronounced among students whose 
parents have a college or advanced degree. Using data from the U.S. National Education Longitudinal Study (NELS), Ma (2009) finds that female students from families with higher socioeconomic status (SES) are less likely to major in technical and life/health science fields, while family SES does not affect male students' major choice in life/health science. Further, Perry et al. (2012) find that additional household income decreases science anxiety and increases science self-concept, but only for boys. Consequently, gender gaps favoring boys are more pronounced in high-SES families compared to low-SES families.

While most studies suggest that the persistent gender gap in STEM fields may be related to gender dynamics in more privileged families, an important exception is a recent study from Werfhorst (2017). It uses Dutch survey data covering cohorts born between the 1930s and 1980s and finds that gender segregation in some fields are less strong among children of higher social origins, because high-SES girls are more likely to enroll in STEM fields, and high-SES boys are more likely to enroll in health fields than their low-SES counterparts. These findings indicate that the effect of family affluence may actually depend on national context.

Despite mixed evidence, the paradox of affluence is found in many societies and calls for a more cautious examination. I next discuss an important explanation derived from cross-national studies and its possible implication at the individual level: the argument of "indulging gendered selves".

\section{Two Mechanisms of "Indulging Gendered Selves"}

To explain the paradox of societal affluence, Charles and Bradley (2009) develop an argument of "indulging gendered selves". It argues that self-expressive cultural values develop in highly affluent, post-industrial societies. Under conditions of material security, careers become less about economic returns but more about self-realization. People are thus encouraged to 
follow their passions. STEM Careers are often regarded as rigid, boring, and without personalities; therefore, in an affluent context that encourages self-expression and selfrealization, such careers are not very appealing (Des Jardins 2010; Osborne, Simon, and Collins 2003; Charles et al. 2014). Consequently, adolescents' interest in STEM careers tends to be lower in more affluent societies. They instead develop pursuits towards self-fulfilling careers, which are more influenced by gendered cultural values.

Charles (2017) further distinguishes two processes happening in affluent societies: women may have greater latitude to indulge their existing gendered passions for non-STEM pursuits because they have fewer concerns about economic returns; on the other hand, these passions themselves can become more gendered, because the meaning of education and work may change to more strongly emphasize personal fulfillment and identity building. Charles argues that these two processes are not mutually exclusive and can both contribute to the affluence effect.

Extending this analysis, this paper argues for two parallel mechanisms to explain the paradox of affluence at the individual level, which can be either reinforcing or countervailing forces. The first mechanism is instrumentalism, which considers the instrumental calculation of material security, occupational risk, and economic returns in developing career aspirations. People in more affluent settings are less pressured to do such instrumental calculation, therefore are more likely to indulge their existing passions that are less instrumental and more selffulfilling. These passions are influenced by gender values and stereotypes in the first place. The instrumentalism mechanism thus leads to indulgence of gendered passions.

The second mechanism is (de)stereotyping, which considers the possibility that more affluent settings cultivate or alleviate gender stereotypes. As Charles et al (2009) suggest, affluence may foster gendered values in the name of self-expression, resulting in a stereotyping 
process. However, as the modernization theory suggests, affluence may bring more gender egalitarian values and refute gender stereotypes, resulting in a de-stereotyping process (Inglehart and Norris 2003; Baker and LeTendre 2005). As career passions can be influenced by gender stereotypes, this mechanism thus partly determines whether gendering of passions would happen in more affluent settings.

This paper points out that behind the observed "paradox of affluence", the two proposed mechanisms do not necessarily work in the same direction. It is possible that affluence actually cultivates more gender egalitarian values, but because the instrumentalism mechanism is stronger, we would still observe greater gender inequality in STEM fields in more affluent contexts. That is to say, with a de-stereotyping mechanism, girls in affluent settings may be more likely to believe that they are as capable as boys in STEM fields, but with an instrumentalism mechanism, they still do not want to pursue such careers because they have the privilege to pursue other life paths that are regarded as more self-expressive. On the other hand, it is also possible that gender stereotypes are indeed stronger in more affluent settings due to norms of self-expression, and this stereotyping process would reinforce the instrumentalism process to intensify gender typing in career aspirations. It is thus crucial to examine the instrumentalism and stereotyping mechanisms separately in order to better understand the effect of affluence and privileges on adolescents' career aspirations.

While cross-national studies rarely analyze these two processes separately, research on family privileges can better examine and distinguish the instrumentalism and (de)stereotyping mechanisms when measurements of individual motivation and stereotype are available. I next discuss these two mechanisms and their measurements in details.

\section{Instrumentalism and (De)stereotyping at the Individual Level}


To explain the effect of family privileges, the first mechanism, instrumentalism, states that family privileges have gendering effect on students' instrumental motivation to pursue STEM careers. In this study, it is measured by students' instrumental motivation to learn math. Instrumental motivation refers to students' drive to learn something because they perceive it as useful to them and to their future studies and careers (OECD 2013). It is thus rationally calculated based on perceived benefits and costs. The Program of International Student Assessment (PISA) 2012 results exhibit that in most countries, after controlling for math performance, girls have lower instrumental motivation to learn math than boys do (OECD 2013).

As suggested by the "indulging gendered selves" argument, post-materialistic cultural norms may generate negative attitudes towards math because like other STEM fields, math is often viewed as rigid, repetitive, and less self-fulfilling (Inglehart and Welzel 2005; Charles et al. 2014). This should affect girls more than boys because math is regarded as gender-nonconfirming for girls. Therefore, we should observe a larger gender gap in instrumental motivation to learn math among more privileged children.

The second mechanism, (de)stereotyping, states that family privileges influence people's endorsement of gender stereotypes. Scholars have found consistent stereotypes about male and female personality and ability across the world: females are believed to be better at nurturing and caring, while males are viewed as more agentic and analytical (Lueptow, Garovich-Szabo, and Lueptow 2001; J. E. Williams and Best 1990; Thébaud and Charles 2018). In particular, there has been a widespread gender-math stereotype that regards math as masculine and believes that male have higher competency than females in math-intensive tasks (Steele 2003; Thoman et al. 2008; Nosek et al. 2009). Research also reveals that gender stereotypes about math and science 
ability contribute to gender differences in test performance (Nguyen and Ryan 2008) and career aspirations (Correll 2004).

Inglehart and Norris (2003) argue that modernization brings changing gender roles and values. They provide evidence that richer, post-industrial societies have more gender egalitarian values than poorer, agrarian and industrial countries. However, using U.S. data from 1950s to late 1990s, Lueptow et al. (2001) find stability in gender stereotypes and even an increase in stereotypes on personality traits of women. Contemporary gender stereotypes in the U.S. tend to view STEM workers, work, and workplace as masculine because these fields are believed to value high levels of intelligence and agency (Thébaud and Charles 2018). Conversely, some researchers argue that in less affluent social contexts where STEM fields are seen as crucial to national development and individual income, STEM careers are seen as more appealing and less gendered (Gharibyan and Gunsaulus 2006). It is not clear that at the individual level, whether family privileges help refute gender stereotypes or foster them through encouraging selfexpression. Therefore, it is yet to be examined whether family privileges bring a stereotyping or de-stereotyping process for individuals.

The two mechanisms, instrumentalism and (de)stereotyping, can work in different directions at the individual level. If family privileges help students to cultivate gender egalitarian views and refute gender stereotype, privileged girls should be less disadvantaged in developing STEM aspirations compared to their male counterparts. However, if at the same time family privileges provide girls with economic security and encourage self-expressive pursuits, girls may become less motivated to pursue lucrative STEM careers and to learn math. The observed relation between family privileges and STEM aspirations thus reflects the combined effect of these two mechanisms. 
Overall, research on family privileges and gender gaps in STEM aspirations has yet to provide clear evidence and explanations to the affluence effect at the individual level. It remains unclear whether the two distinct mechanisms, instrumentalism and (de)stereotyping, work in the same or different directions. To fill in this gap, I use nationally representative data from China to examine the effect of family privileges at the individual level. In the next section, I explain why China provides a particularly interesting case and propose hypotheses based on previous literature and the Chinese context.

\section{THE CHINESE CONTEXT}

China presents a particularly interesting case to study family privileges, gender inequality in STEM aspirations, and the two hypothesized mechanisms for four reasons.

First, contemporary Chinese society suffers from severe gender inequality and stereotypes. Traditional Confucian values deeply influenced Chinese culture with highly gendered values and distinct gender roles (Skromme Granrose 2007; Liu 2014). Although the Communist Party made efforts to promote gender egalitarian practices during the socialist period, this progress slowed down since the market reform in the late 1970s (Liu 2014; Hannum and Xie 1994). Recent evidence even shows a resurgence of traditional gender values and an expansion of gender inequality (Hannum, Kong, and Zhang 2009; Zhang and Hannum 2015). According to the Global Gender Gap Report 2018, China ranked 103 out of 149 countries in a composite index indicating national gender equality in economics, politics, education, and health (World Economic Forum 2018). Evidence shows significant gender discrimination and segregation in contemporary Chinese labor market. Gender discrimination is strikingly common and explicit in recruiting advertisements (Human Rights Watch 2018; Gao 2008; Kuhn and Shen 2013), and 
men are disproportionately distributed in more technical and lucrative jobs than women (Xiu and Gunderson 2015; Summerfield et al. 2011). Therefore, China provides an important context in studying gender gaps in STEM aspirations in the first place.

Second, despite rapid economic progress and sustained reduction in poverty, China is still a developing country with huge economic inequality and a large poverty population. According to the World Bank Group (2019), 373.1 million Chinese live under the Upper Middle Income Class Poverty Line (\$5.5 per day) in 2015. Xie and Zhou (2014) point out that China’s income inequality has reached very high levels with a GINI coefficient over 0.5 , and a substantial part of this income inequality is rooted in regional disparities and the rural-urban gap. Basic economic security is far from guaranteed for many Chinese families, which should motivate less-privileged children to concern more about economic return of careers. Therefore, there should be a solid basis for the instrumentalism mechanism.

Based on this context and previous literature on the paradox of affluence at the individual level, I propose the following hypotheses:

Hypothesis 1a: Family privileges are associated with a lower level of STEM aspirations among Chinese students.

Hypothesis 1b: The negative association between family privileges and STEM aspirations is stronger among girls than among boys, leading to larger gender differences in STEM aspirations among more privileged students.

As the instrumentalism mechanisms suggests, the gendering effect of family affluence is partly linked to students' instrumental motivation:

Hypothesis 2a: Family privileges are associated with a lower level of instrumental motivation to learn math. 
Hypothesis 2b: The negative association between family privileges and instrumental motivation to learn math is stronger among girls than boys, leading to a larger gender gap in instrumental motivation among more privileged students.

Third, some evidence also points to differential gender values among Chinese families with differential socioeconomic status. Persistent son preference leads to widespread practices of sexselective infanticide and abortion in rural China (J. Li and Lavely 2009; Das Gupta et al. 2003). Parents are found to have higher education expectation for sons than daughters in rural areas (Hannum, Kong, and Zhang 2009). On the other hand, equally high educational aspirations are found among male and female only children in urban China (Tsui and Rich 2002). Girls' educational opportunities are found to be more responsive than boys' to better household economic status (Hannum 2005). This shows that family privileges may help girls to refute gendered values and expectations. Therefore, China provides an important context for studying the potential de-stereotyping mechanism of family privileges. I thus propose the following hypotheses:

Hypothesis 3a: Family privileges are associated with lower odds of endorsing gender-math stereotype among Chinese students.

Hypothesis 3b: The negative association between family privileges and gender-math stereotype is stronger among girls than boys.

Last, China has a highly standardized secondary education system and a rigorous national math curriculum, imposing universal standards and exposure to math for boys and girls (Tsui 2007). Before students step into different academic streams in high school, there should be minimal gender differences in math exposure at school. Education surveys indeed show that young girls in China achieve on a par with boys in math and exhibit higher math competency 
compared to their peers in Western developed countries. The PISA 2015 results show that in three Mainland Chinese cities (Shanghai, Guangdong, and Beijing), girls achieve the same level of math performance as boys (OECD 2016). Tsui (2007) also finds no gender difference in mean college entrance examination math scores among high-school seniors in Wuhan. This provides a more interesting context to explore the stereotyping and instrumentalism mechanisms when no gender disparity in math competency is observed.

\section{DATA AND METHOD}

\section{Data}

This study employs the China Education Panel Survey (CEPS), a large-scale national survey conducted by the National Survey Research Center (NSRC) at Renmin University of China. CEPS applied a stratified, multistage sampling design, randomly selecting a nationally representative sample of approximately 20,000 students in 438 classes of 112 schools in 28 county-level administrative units in mainland China. This study analyzes its baseline survey, which was completed in the 2013-2014 academic year with students in 7th and 9th grades. Only cases with complete information on all variables are included in this study, resulting in 18,032 valid cases. $^{1}$

\section{Dependent Variables}

Three dependent variables are used in the analysis: student's aspiration in science and engineering, instrumental motivation to learn math, and endorsement of gender-math stereotype.

Aspiration in science and engineering is measured by the question "What do you want to do in the future?" Ten occupation categories are provided: $1=$ Government officials, $2=$ Corporate managers, $3=$ Scientists or engineers, $4=$ Teachers, doctors, or lawyers, $5=$ Designers, $6=$ Artist 
performers, $7=$ Professional athletes, $8=$ Technicians including drivers, $9=$ Others, and $10=$ It doesn't matter. A dichotomous variable is then constructed, which equals to 1 if the student chooses " $3=$ Scientists or engineers" and 0 otherwise.

Instrumental motivation to learn math is measured by the question "Do you agree with the following statement: math is very helpful to my future". The answer is on a four-level scale: $1=$ Strongly disagree, $2=$ Disagree, $3=$ Agree, and $4=$ Strongly agree. A larger number indicates a higher level of instrumental motivation to learn math. This variable is treated as an ordinal variable in the analysis.

Endorsement of gender-math stereotype is reported by students from the question "Do you think boys are better at math than girls?" $(1=\mathrm{Yes}, 0=\mathrm{No})$.

\section{Independent variables}

The key independent variable in the analytic models is female $(\operatorname{coded} 0=$ Male, $1=$ Female).

CEPS does not explicitly ask about family wealth or income. Therefore, I use a set of variables to measure family privileges. The first variable, parental education, is derived from the question "what is your mother/father's highest education level?" Answers are chosen from nine categories, ranging from "no education at all" to "postgraduate education or higher". The higher one between mother's and father's education levels is kept, recoded into The International Standard Classification of Education (ISCED) levels, and converted into years using the mapping procedure suggested by $\operatorname{OECD}(2014,444)$.

Education as a form of human capital has been found to be highly correlated with personal income in China (Xie and Zhou 2014; Zhou 2000; H. Li 2003). Using retrospective information from a sample of about 5,000 residents from 20 Chinese cities, Zhou (2000) finds that during the 
1990s, a senior high education increases one's income by $16 \%$ and a college education increases one's income by 20\%. A recent study from Xie and Zhou (2014) using China Family Panel Study 2010 further reveals that about $15 \%$ of income inequality in China can be explained by the education level of the family head. Therefore, parental education is a good proximate of family affluence.

Two additional variables are included to measure student's privileges in education resources at home: whether the student has his or her own study desk $(1=\mathrm{Yes}, 0=\mathrm{No})$, and number of books at home ( $1=$ Very few; $2=$ Relatively few; $3=\mathrm{A}$ normal amount; $4=$ Many; $5=\mathrm{A}$ lot). A recent study by Charles (2017) using cross-national data finds that Internet access at home has a negative effect on STEM aspirations, and this effect is especially strong among girls. Charles argues that home Internet access may increase students' exposure to gender stereotypes disseminated online and Western cultural values that encourage gendered self-expression. To test such effect in China, Internet access $(1=\mathrm{Yes}, 0=\mathrm{No})$ is included as a measure of family privileges.

Five more variables are included: rural hukou ${ }^{2}$, ethnic minority, migrant, only child, and living with both parents. Rural residents in China are significantly disadvantaged in income (Xie and Zhou 2014) and education (Lu and Zhou 2013; Zhao et al. 2014). Research has shown significant and increasing ethnic disparities in education since the 1980s (Hannum 2002). Migrant students are found to be disadvantaged in school performance (Lu and Zhou 2013; Xu and $\mathrm{Wu} 2016$ ). Further, students who are only children and living with both parents are found to have higher academic performance in China (Tsui and Rich 2002; Zhao et al. 2014). Therefore, these five variables are included as additional measures of family privileges.

\section{Control variables}


Test scores of Math, Chinese, and English subjects from the most recent mid-term exams are included to control for student's academic performance. The scores are standardized within each grade and school with an average at 70 and standard deviation at 10. Standardized scores from a universal cognitive ability test are included to control for the cognitive ability of students. Student effort may be directly associated with learning attitudes; therefore, I include number of hours spent on homework per week to control for student's learning effort. Grade is also included as a control variable $(1=$ Grade $9,0=$ Grade 7$)$.

A set of school-level variables are included to control for school-level heterogeneity, including school ranking (rated by school administrator in five levels and treated as a continuous variable), percentage of students with rural hukou, percentage of students with local residence status (non-migrant), percentage of students living with both parents, and whether the school is a public school, boarding school, and located in an urban area.

\section{Analytic Strategy}

I first use a logistic regression model with the full sample to investigate the main effects of gender and family privileges on students' science/engineering aspiration. I then run two separate models using the female and male subsamples to show the effect of family privileges separately for girls and boys. I also use a set of heterogenous choice models with interaction terms between each privilege measure and gender to test whether observed gender differences in estimated effects are statistically significant. ${ }^{3}$

To examine the instrumentalism mechanism, I first use an ordinal logistic regression model to investigate the main effects of gender and family privileges on student's instrumental motivation to learn math, and then run separate models using the female and male subsamples. Similarly, to examine the stereotyping mechanism, I first use a logistic regression model with the 
full sample to investigate the main effects of gender and family privileges on student's endorsement of gender-math stereotype, and then run two separate models using the female and male subsamples. ${ }^{4} \mathrm{~A}$ set of heterogenous choice models with interaction terms between each privilege measure and gender are then used to test whether gender differences in estimated effects are statistically significant.

Observations in CEPS are not sampled with equal probability; individual sampling weights are used in order to achieve unbiased estimates. Further, students are clustered in schools, resulting in dependence of errors within schools; therefore, cluster-robust standard errors at the school level are used in all models. ${ }^{5}$

\section{FINDINGS}

\section{Descriptive statistics}

Table 1 shows descriptive statistics of main variables. Column 1 exhibits results from the full sample, column 2 exhibits results from the female subsample, and column 3 exhibits results from the male subsample. Column 4 shows results from a two-tailed t-test indicating whether gender differences are statistically significant.

\section{[TABLE 1 ABOUT HERE]}

Results from the full sample exhibit that $8.1 \%$ of students have career aspirations in science and engineering. Around $55.3 \%$ of students endorse the gender-math stereotype, meaning that over half of students have the essentialist belief that boys are better in math than girls. The mean level of instrumental motivation to learn math is 3.182 with a standard deviation of 0.850 . The average year of parental education is around 10.862, about two years into high school. When it comes to education resources at home, $78.3 \%$ of students have their own study desks, and $60.3 \%$ have access to Internet. The average level of book resource is 3.165 (out of 5) with a standard 
deviation of 1.205 . For the other privilege measures, $17.5 \%$ of students are migrant children, $8.3 \%$ are ethnic minorities, $54.9 \%$ have rural hukou, $44.0 \%$ are only children, and $77.2 \%$ live with both parents.

When we compare results from the female and male subsamples, boys are clearly much more likely to have aspirations in science and engineering than girls: about $13.5 \%$ of boys have such aspirations while only $2.2 \%$ of girls do. Boys are also more likely to endorse the gendermath stereotype: $60.0 \%$ of boys have such stereotypes while $50.3 \%$ of girls do. Further, boys have slightly stronger instrumental motivation to learn math than girls do: the average level of instrumental motivation is 3.204 for boys and 3.159 for girls. Although this difference is statistically significant, the gender effect size measured by Cohen's $d$ is 0.053 and is considered small (Cohen 1988).

There is no significant gender difference in parental education, which is reasonable if we assume no correlation between parental education and student gender. However, girls receive better education resources than boys: girls are more likely to have their own study desks (female $=79.4 \%$, male $=77.3 \%$ ), and families with girls have more books at home (female $=3.225$, male $=3.110$ ). Girls are also slightly more likely to live with both parents (female $=78.3 \%$, male $=76.2 \%$ ). This may be a selection effect suggesting that girls with extremely poor resources are excluded from the sample. Further, girls are much less likely to be only children (female $=39.8 \%$, male $=47.7 \%$ ), which is predictable considering the persistent son preference in China (Das Gupta et al. 2003). There is no significant gender difference in migrant status, minority status, and rural hukou status. When it comes to academic performance, girls spend more time on homework and perform significantly better in all three subjects, although no gender difference is found in cognitive test scores. 


\section{Predicting Aspiration in Science and Engineering}

[TABLE 2 ABOUT HERE]

Table 2 exhibits results from logistic regression models predicting student aspiration in science and engineering. Column 1 presents results using the full sample, while columns 2 and 3 present results from the female and male subsamples. To facilitate interpretation, odds ratios (OR) instead of coefficients are reported in all models. An odds ratio greater than 1 indicates a positive correlation, and a larger number indicates a stronger effect. Conversely, an odds ratio smaller than 1 indicates a negative correlation, and a smaller number indicates a stronger effect. Column 4 reports whether gender differences in estimated effects are statistically significant.

The full sample analysis shows a significant gender gap in student aspirations. The odds for a female student to have science/engineering aspirations are about one eighth of that of a male student $(\mathrm{OR}=0.128)$.

Contrary to hypothesis 1a, family privileges such as parental education and number of books at home are positively correlated with the odds of having science/engineering aspiration. One year increase in parental education is correlated with a $4.7 \%$ increase in the odds of having science/engineering aspiration $(\mathrm{OR}=1.047)$. One level increase in the number of books at home is correlated with a $9.3 \%$ increase in the odds of having science/engineering aspiration $(\mathrm{OR}=1.093)$. On the other hand, home Internet access is correlated with an $20.8 \%$ decrease in the odds of having science/engineering aspiration $(\mathrm{OR}=0.792)$. This is consistent with hypothesis $1 \mathrm{a}$ and Charles (2017), which finds a negative effect of Internet access on students' STEM aspirations in 32 countries. 
None of the other privilege measures show significant effect. Although this study does not focus on control variables, it is worth mentioning that $9^{\text {th }}$ grade students are $23.9 \%$ less likely to have science/engineering aspiration than $7^{\text {th }}$ grade students $(\mathrm{OR}=0.761)$. Students with higher math test scores $(\mathrm{OR}=1.041)$ and cognitive ability test scores $(\mathrm{OR}=1.105)$ are more likely to have science/engineering aspiration.

Separate analyses using female and male subsamples show gendered effects of parental education: one year increase in parental education is correlated with a $10.5 \%$ increase in the odds of having science/engineering aspiration for girls $(\mathrm{OR}=1.105)$ and a $3.8 \%$ increase for boys $(\mathrm{OR}=1.038)$. Analysis on marginal effects shows that the observed difference is mainly because of girls' low aspiration in the first place. Holding other variables at mean, when parental education increase from 12 years to 16 years, the predicted probability of having science/engineering aspiration rises from $2.0 \%$ to $3.0 \%$ for girls and from $13.2 \%$ to $15.0 \%$ for boys. Although the increase for girls is large relative to itself (a $50 \%$ increase), the absolute change in probabilities is small. ${ }^{6}$

Further, although there are observed differences between boys and girls in the effects of being only child, home Internet access, and number of books at home, these differences are not statistically significant when tested in heterogenous choice models. Therefore, contrary to hypothesis $1 \mathrm{~b}$, we do not observe a larger gender difference in STEM aspirations among privileged students. However, it is possible that the two hypothesized mechanisms, stereotyping and instrumentalism, work in opposite directions and neutralize each other. I next examine each mechanism separately.

\section{Instrumentalism: Predicting Instrumental Motivation to Learn Math}

[TABLE 3 ABOUT HERE] 
I examine the instrumentalism mechanism by applying a set of ordered logistic regression models to predict instrumental motivation to learn math. Table 3 shows results from three separate models using the full, female, and male samples, respectively.

Results from the full sample clearly show a gender difference: the odds of girls to have a combination of higher levels as opposed to the combination of lower levels of instrumental motivation is $84.4 \%$ of that of boys. For example, the odds of girls to have the highest level of instrumental motivation (as opposed to having the lower three levels) are $84.4 \%$ of that of boys $(\mathrm{OR}=0.844)$. Likewise, the odds of girls to have level 3 or 4 (as opposed to level 1 or 2 ) of instrumental motivation are also $84.4 \%$ of that of boys.

When it comes to effects of family privileges on students' instrumental motivation, we observe even more interesting gender differences. First, inconsistent with hypothesis $2 \mathrm{a}$, a greater number of books at home is correlated with greater odds of having a higher level of instrumental motivation $(\mathrm{OR}=1.140)$, and this effect is significantly stronger among boys $(\mathrm{OR}=1.151)$ than girls $(\mathrm{OR}=1.131)$. This means that as the number of books at home increases, students' instrumental motivation to learn math increases faster for boys, resulting in an expanding gender gap.

Second, partly consistent with hypotheses $2 \mathrm{a}$ and $2 \mathrm{~b}$, being ethnic minority and having rural hukou are both positively correlated with instrumental motivation to learn math, but only for girls: girls who are ethnic minorities are $40.8 \%$ more likely to have higher levels of instrumental motivation compare to girls who are non-minorities $(\mathrm{OR}=1.408)$; girls who have rural hukou are $12.2 \%$ more likely to have higher levels of instrumental motivation compared to girls with non-rural hukou $(\mathrm{OR}=1.122)$. Ethnic minorities and rural students are less privileged in China, thus they are more likely to pursue lucrative careers to secure material returns. Therefore, 
they regard math as more useful to their future and become more motivated to learn math. This mechanism is only evident among girls but not boys, meaning that the gender gap in instrumental motivation is larger among privileged students who are non-ethnic and non-rural compared to ethnic and rural students.

Last, home Internet access is negatively correlated with the odds of having higher levels of instrumental motivation to learn math $(\mathrm{OR}=0.803)$, and this association is slightly stronger for girls $(\mathrm{OR}=0.799)$ than for boys $(\mathrm{OR}=0.810)$. This provides evidence for an instrumentalism mechanism behind the Internet effect on STEM aspirations: Internet access may increase exposure to culture values of self-expression that views STEM careers as less appealing, thus decreasing students' instrumental motivation to learn math. Girls are more vulnerable to this effect because math is viewed as gender-non-confirming for them.

\section{De-stereotyping: Predicting Endorsement of Gender-Math Stereotype}

\section{[TABLE 4 ABOUT HERE]}

To examine the de-stereotyping mechanism, I use a set of logistic regression models to predict students' endorsement of gender-math stereotype. Table 4 exhibits results using the full, female, and male samples, respectively. The full sample model shows a significant gender difference: girls are $35.0 \%$ less likely to endorse gender-math stereotype than boys $(\mathrm{OR}=0.650)$.

When it comes to privilege measures, partly consistent with hypotheses $3 \mathrm{a}$ and $3 \mathrm{~b}$, we observe a de-stereotyping effect of family privileges, but for girls only. First, one year increase in parental education is correlated with a $3.8 \%$ decrease in the odds of endorsing gender-math stereotype for girls ( $\mathrm{OR}=0.962)$, while no parental education effect is found for boys. Second, one level increase in number of books at home is correlated with a $6.5 \%$ decrease in girls' odds 
of endorsing gender-math stereotype $(\mathrm{OR}=0.935)$ but does not bring significant changes for boys. These results indicate that family privileges such as parental education and home education resource help cultivate gender egalitarian values and refute gender stereotype for girls.

Further, home Internet access increases the odds of endorsing gender-math stereotype by $9.3 \%(\mathrm{OR}=1.093)$. This effect is even greater for girls $(\mathrm{OR}=1.184)$, although the gender difference is not statistically significant. This provides further evidence to a stereotyping mechanism behind the Internet effect on STEM aspirations and findings in Charles (2017): frequent use of Internet may increase students' exposure to contents and values that foster gender stereotypes.

\section{DISCUSSION}

This study provides important evidence regarding the effect of family privileges on gender differences in STEM aspirations. First, family privileges such as parental education and books at home are positively correlated with STEM aspirations. It is reasonable that STEM aspirations require certain privileges. Parents' knowledge in STEM fields can help cultivate children's STEM aspirations; further, STEM aspirations usually require an expectation in college education (Xie and Shauman 2003), while students with fewer education resources can be disadvantaged in this regard. Therefore, in relatively less developed societies such as China, privileges in parental education and family education resources help cultivate STEM aspirations rather than discourage it through self-expressive values. This may not be true in more developed societies where basic education resources can be guaranteed and college education is more common.

Second, extending Charles and Bradley (2009) and Charles (2017), findings suggest that the two hypothesized mechanisms, de-stereotyping and instrumentalism, are distinct forces that 
can work in different directions. The effect of family privileges on STEM aspirations thus depends on the combination of these two mechanisms. Less privileged girls such as those who are ethnic minorities or with rural hukou have greater math-learning motivation as they strongly believe that math is useful to their future, indicating an instrumentalism mechanism. As gender inequality is more severe in these disadvantaged groups, they may regard STEM careers as opportunities for economic security. Conversely, their privileged peers have lower instrumental motivation to learn math, likely because they have more latitude to indulge gendered passions. Chinese scholars have pointed to a resurgence of traditional gender values in the market reform era (Zhang and Hannum 2015; Hannum, Kong, and Zhang 2009; Liu 2014). The gendered effect of family privileges in instrumental motivation may thus reflect differences in career and family plans. Privileged girls may expect to pursue non-STEM careers that are perceived as more selfexpressive; they may also expect to devote themselves to domesticity as opposed to the labor market. Both choices can be seen as a form of indulgence of gendered passions as suggested in Charles and Bradley (2009).

On the other hand, girls with privileges such as higher parental education and more books at home enjoy a de-stereotyping process, as they are less likely to endorse the gender-math stereotype. This suggests that family privileges do not necessarily result in more gendered values and aspirations; conversely, they can help cultivate gender-egalitarian values and refute gender stereotypes. In other words, family privileges may encourage indulgence of gendered passions via the instrumentalism mechanism, but at the same time discourage gendering of passions via the de-stereotyping mechanism. The ultimate effect of family privileges on STEM aspirations thus depend on the relative strengths of these two mechanisms and may vary according to social contexts. 
It is worth noting that some effects of family privileges are clearly gendered while others are not. For example, the negative effects of having rural hukou and being ethnic minority on instrumental motivation are only evident among girls. One possible explanation is that ethnic and rural girls in China have more urgent needs to get into STEM fields than boys, because gender inequality in resource distribution is more severe among these groups (Hannum, Kong, and Zhang 2009; Hannum 2002). The effects of higher parental education and more books at home on refuting gender-math stereotype are also only evident among girls. This is likely because girls are described as the "inferior group" in the gender-math stereotype and suffer from discrimination associated with such stereotype, thus both girls and their parents are more motivated to refute such stereotype when they have privileges and resources. The positive effect of books on STEM aspirations, on the other hand, is not gendered, showing that education resources cultivate STEM aspirations similarly for boys and girls.

Another important finding is about the effect of home Internet access. Partly consistent with findings in Charles (2017), home Internet access exhibits a negative effect on STEM aspirations among Chinese students. Charles suggests that this is because affluent Western values are disproportionately represented on the Internet. Students who access Internet frequently and intensively become more exposed to Western stereotypes that view STEM careers as boring, difficult, and masculine. Moreover, students with home Internet access may be more exposed to Western individualistic values that encourage gendered self-expression and self-realization (Inglehart and Welzel 2005).

This study shows that both stereotyping and instrumentalism mechanisms contribute to the gendering effect of home Internet access. Students with home Internet access are more likely to endorse gender-math stereotype, and also view math as less useful to their future. The latter 
effect is even stronger among girls, resulting in a larger gender gap in instrumental motivation to learn math among students with home Internet access. This is as expected since math is viewed as non-gender-conforming for girls. Extending Charles (2017), these findings suggest that home Internet access may encourage gendered career aspirations through both indulgence of gendered passions and gendering of passions.

\section{CONCLUSION AND IMPLICATIONS}

Extending comparative literature about the gendering effect of social affluence on STEM aspirations, this study looks into the individual-level effect of family privileges on students' STEM aspirations in China. Two mechanisms are proposed and examined to better understand the argument of "indulging gendered selves" in Charles and Bradley (2009): instrumentalism, which tests how family privileges are associated with instrumental calculation of perceived returns, and (de)stereotyping, which tests how family privileges are associated with endorsement of gender stereotype. Results show that these two mechanisms are two distinct forces that can work in different directions. Girls with family privileges can be less likely to endorse gendermath stereotype, but at the same time less motivated to learn math, possibly because they are more encouraged to pursue gendered passions as a form of self-expression. The effect of family privileges on gender differences in STEM aspirations thus depend on the tension between these two mechanisms.

This study has certain limitations. First, the CEPS data only measure students' instrumental motivation to learn math, which reflects the rational calculation based on perceived usefulness, but not their intrinsic interest in math. OECD (2013) reports that intrinsic interest is equally if not more important than instrumental motivation in determining students' learning attitudes and 
outcomes. Future studies could incorporate intrinsic interests to better analyze the stereotyping mechanism and gendering of passions. Second, the categorization of career aspirations in the CEPS survey is not ideal in distinguishing STEM and non-STEM careers. For example, teachers, lawyers, and doctors are put into one single category, while these three careers may have very different social status. Moreover, becoming doctors may require much more STEM training. Future surveys and studies should include more detailed career categories for a more nuanced analysis of STEM aspirations. Third, while Charles (2017) suggests that the gendering effect of home Internet access is rooted in more exposure to Western culture values, the CEPS survey did not ask students about their purposes of using the Internet and types of online contents they access. Future surveys should consider including more detailed questions regarding home Internet usage in order to better understand the gendered effect of home Internet access.

Despite the limitations, findings from this study have important implications. Less privileged girls, such as those with lower parental education and fewer books at home, are more likely to face with gender-math stereotype. On the other hand, although family privileges help cultivate more gender egalitarian values, they can still encourage gendered pursuits in the name of self-expression and self-realization when basic life needs are secured. Moreover, modern information technology such as the Internet may exacerbate gender inequality in STEM fields by exposing privileged students in less-developed societies to stereotypical contents and values that are overrepresented on the Internet. To effectively encourage young girls to pursue careers that are conventionally perceived masculine, it is thus crucial to design educational and social programs focused on eliminating gender stereotypes, building desegregated gender cultures, and constructing STEM as non-gendered fields. 


\section{NOTES}

1. The percentage of missing data is less than $4.0 \%$ for each variable. Models were also run on the entire sample to check for biases due to missing data using the maximum likelihood method. No substantive difference in the relative magnitude or significance of estimates was found.

2. Hukou is the household registration system in mainland China, which officially identifies a person as a resident of a particular area.

3. Mustillo et al. (2018) warn that coefficients of interaction terms should not be used to draw conclusions about interaction effects in logit models. This paper follows Williams (2009) to use heterogenous choice models allowing residual variability to vary according to gender; coefficients of interaction terms between gender and family privilege measures are used to test whether there is a gendered effect of family privileges.

4. One reviewer points out that parental education could have a curvilinear relationship with student aspiration, stereotype, and motivation. I thus tested this possibility by adding a quadratic term of parental education to the logistic regression models. Results do not show significant effect of the quadratic term, and goodness-of-fit tests using Akaike Information Criterion (AIC) show that models without quadratic terms are better fits.

5. I also applied random effects models with random intercepts at the school level to check for robustness of the results. No substantial difference in the magnitude or significance of estimates were found in the variables at interest.

6. For a detailed explanation about differences between marginal effects on probability and multiplicative effects based on odds ratios, please see Buis (2010). 


\section{ABOUT THE AUTHOR}

Ran Liu is an assistant professor at the Department of Educational Policy Studies at the University of Wisconsin-Madison. Her research interests include gender, education, East Asia, and quantitative methods. Her recent work has appeared in Comparative Education Review and American Educational Research Journal. 


\section{Reference:}

Baker, David, and Gerald K LeTendre. 2005. National Differences, Global Similarities: World Culture and the Future of Schooling. Stanford University Press.

Buis, Maarten L. 2010. "Stata Tip 87: Interpretation of Interactions in Nonlinear Models." The Stata Journal: Promoting Communications on Statistics and Stata 10 (2): 305-8. doi:10.1177/1536867X1001000211.

Charles, Maria. 2017. "Venus, Mars, and Math: Gender, Societal Affluence, and Eighth Graders' Aspirations for STEM." Socius : Sociological Research for a Dynamic World 3 (December): 116. doi:10.1177/2378023117697179.

Charles, Maria, and Karen Bradley. 2009. "Indulging Our Gendered Selves? Sex Segregation by Field of Study in 44 Countries." American Journal of Sociology 114 (4): 924-76. doi:10.1086/595942.

Charles, Maria, and David B Grusky. 2004. Occupational Ghettos: The Worldwide Segregation of Women and Men. Vol. 200. Stanford, CA: Stanford University Press.

Charles, Maria, Bridget Harr, Erin Cech, and Alexandra Hendley. 2014. "Who Likes Math Where? Gender Differences in Eighth-Graders' Attitudes around the World." International Studies in Sociology of Education 24 (1): 85-112. doi:10.1080/09620214.2014.895140.

Correll, Shelley J. 2004. "Constraints into Preferences: Gender, Status, and Emerging Career Aspirations.” American Sociological Review 69 (1): 93-113. doi:10.1177/000312240406900106.

Das Gupta, Monica, Jiang Zhenghua, Li Bohua, Xie Zhenming, Woojin Chung, and Bae Hwa-Ok. 2003. "Why Is Son Preference so Persistent in East and South Asia? A Cross-Country Study of China, India and the Republic of Korea." Journal of Development Studies 40 (2): 153-87. doi:10.1080/00220380412331293807.

Des Jardins, Julie. 2010. The Madame Curie Complex: The Hidden History of Women in Science. The Feminist Press at CUNY.

Gao, Zhihong. 2008. "Gender Discrimination in Chinese Recruitment Advertisements: A Content Analysis.” Journal of Asia-Pacific Business 9 (4): 395-418. doi:10.1080/10599230802453638.

Gharibyan, Hasmik, and Stephan Gunsaulus. 2006. "Gender Gap in Computer Science Does Not Exist in One Former Soviet Republic.” ACM SIGCSE Bulletin 38 (3): 222. doi:10.1145/1140123.1140184.

Hannum, Emily. 2002. "Educational Stratification by Ethnicity in China: Enrollment and Attainment in the Early Reform Years." Demography 39 (1): 95-117.

- 2005. "Market Transition, Educational Disparities, and Family Strategies in Rural China: New Evidence on Gender Stratification and Development." Demography 42 (2): 275-99.

Hannum, Emily, Peggy Kong, and Yuping Zhang. 2009. "Family Sources of Educational Gender Inequality in Rural China: A Critical Assessment." International Journal of Educational Development 29 (5): 474-86. doi:10.1016/j.ijedudev.2009.04.007.

Hannum, Emily, and Yu Xie. 1994. "Trends in Educational Gender Inequality in China: 1949-1985." Research in Social Stratification and Mobility 13: 73-98.

Human Rights Watch. 2018. "Only Men Need Apply": Gender Discrimination in Job Advertisements in China.

Inglehart, Ronald, and Pippa Norris. 2003. Rising Tide: Gender Equality and Cultural Change Around the World. Cambridge, UK: Cambridge University Press.

Inglehart, Ronald, and Christian Welzel. 2005. Modernization, Cultural Change, and Democracy: The 
Human Development Sequence. Cambridge, UK: Cambridge University Press.

Kuhn, Peter, and Kailing Shen. 2013. "Gender Discrimination in Job Ads: Evidence from China." The Quarterly Journal of Economics 128 (1): 287-336. doi:10.1093/qje/qjs046.

Li, Haizheng. 2003. "Economic Transition and Returns to Education in China." Economics of Education Review 22 (3): 317-28. doi:10.1016/S0272-7757(02)00056-0.

Li, Jianghong, and William Lavely. 2009. "Village Context, Women's Status, and Son Preference among Rural Chinese Women.” Rural Sociology 68 (1): 87-106. doi:10.1111/j.15490831.2003.tb00130.x.

Liu, Fengshu. 2014. "From Degendering to (Re)Gendering the Self: Chinese Youth Negotiating Modern Womanhood." Gender and Education 26 (1): 18-34. doi:10.1080/09540253.2013.860432.

Lu, Yao, and Hao Zhou. 2013. "Academic Achievement and Loneliness of Migrant Children in China: School Segregation and Segmented Assimilation." Comparative Education Review 57 (1): 85116. doi:10.1086/667790.

Lueptow, Lloyd B, Lori Garovich-Szabo, and Margaret B Lueptow. 2001. "Social Change and The Persistence of Sex Typing: 1974-1997." Social Forces 80 (1): 1-36.

Ma, Yingyi. 2009. "Family Socioeconomic Status, Parental Involvement, and College Major Choicesgender, Race/Ethnic, and Nativity Patterns.” Sociological Perspectives 52 (2): 211-34. doi:10.1525/sop.2009.52.2.211.

National Science Foundation. 2018. "Science and Engineering Indicators 2018." https://www.nsf.gov/statistics/2018/nsb20181/digest/sections/u-s-s-e-workforce-trends-andcomposition.

Nguyen, Hannah-Hanh D, and Ann Marie Ryan. 2008. "Does Stereotype Threat Affect Test Performance of Minorities and Women? A Meta-Analysis of Experimental Evidence." The Journal of Applied Psychology 93 (6): 1314-34. doi:10.1037/a0012702.

Nosek, Brian A, Frederick L Smyth, N Sriram, Nicole M Lindner, Thierry Devos, Alfonso Ayala, Yoav Bar-Anan, et al. 2009. "National Differences in Gender-Science Stereotypes Predict National Sex Differences in Science and Math Achievement." Proceedings of the National Academy of Sciences of the United States of America 106 (26): 10593-97. doi:10.1073/pnas.0809921106.

OECD. 2013. PISA 2012 Results: Ready to Learn: Students' Engagement, Drive and Self-Beliefs. Vol. III. Paris: PISA, OECD Publishing. 2015. The ABC of Gender Equality in Education: Aptitude, Behavior, Confidence. Paris: PISA, OECD Publishing. 2016. PISA 2015 Results (Volume I): Excellence and Equaty in Education. Paris: PISA, OECD Publishing.

Osborne, Jonathan, Shirley Simon, and Sue Collins. 2003. "Attitudes towards Science: A Review of the Literature and Its Implications.” International Journal of Science Education 25 (9): 1049-79. doi:10.1080/0950069032000032199.

Penner, Andrew M., and Marcel Paret. 2008. "Gender Differences in Mathematics Achievement: Exploring the Early Grades and the Extremes.” Social Science Research 37 (1): 239-53. doi:10.1016/j.ssresearch.2007.06.012.

Perry, Brea L., Tanja Link, Christina Boelter, and Carl Leukefeld. 2012. "Blinded to Science: Gender Differences in the Effects of Race, Ethnicity, and Socioeconomic Status on Academic and Science Attitudes among Sixth Graders." Gender and Education 24 (7): 725-43. doi:10.1080/09540253.2012.685702. 
Riegle-Crumb, Catherine, Chelsea Moore, and Aida Ramos-Wada. 2011. "Who Wants to Have a Career in Science or Math? Exploring Adolescents' Future Aspirations by Gender and Race/Ethnicity." Science Education 95 (3): 458-76. doi:10.1002/sce.20431.

Sikora, Joanna, and Artur Pokropek. 2012. "Gender Segregation of Adolescent Science Career Plans in 50 Countries." Science Education 96 (2): 234-64. doi:10.1002/sce.20479.

Skromme Granrose, Cherlyn. 2007. "Gender Differences in Career Perceptions in the People's Republic of China." Career Development International 12 (1): 9-27. doi:10.1108/13620430710724802.

Steele, Jennifer. 2003. "Children's Gender Stereotypes about Math: The Role of Stereotype Stratification.” Journal of Applied Social Psychology 33 (12): 2587-2606. doi:10.1111/j.15591816.2003.tb02782.x.

Summerfield, Gale, Xiao-Yuan Dong, Nahid Aslanbeigui, and Jie Hu. 2011. "Wage Differentials, Occupational Segregation, and Gendered Creativity Perceptions in the Chinese Science and Technology Sector: Beijing and Wuhan.” Eastern Economic Journal 37 (2): 178-96.

Thébaud, Sarah, and Maria Charles. 2018. "Segregation, Stereotypes, and STEM." Social Sciences 7 (7): 111. doi:10.3390/socsci7070111.

Thoman, Dustin B., Paul H. White, Niwako Yamawaki, and Hirofumi Koishi. 2008. "Variations of Gender-math Stereotype Content Affect Women's Vulnerability to Stereotype Threat." Sex Roles 58 (9-10): 702-12. doi:10.1007/s11199-008-9390-x.

Tsui, Ming. 2007. "Gender and Mathematics Achievement in China and the United States." Gender Issues 24 (3): 1-11. doi:10.1007/s12147-007-9044-2.

Tsui, Ming, and Lynne Rich. 2002. "The Only Child and Educational Opportunity for Girls in Urban China." Gender \& Society 16 (1): 74-92. doi:10.1177/0891243202016001005.

van de Werfhorst, Herman G. 2017. "Gender Segregation across Fields of Study in Post-Secondary Education: Trends and Social Differentials.” European Sociological Review 33 (3): 449-64. doi:10.1093/esr/jcx040.

Williams, John E, and Deborah L Best. 1990. Sex and Psyche: Gender and Self Viewed Cross-Culturally. Thousand Oaks, CA: Sage Publications, Inc.

Williams, Richard. 2009. "Using Heterogeneous Choice Models to Compare Logit and Probit Coefficients across Groups.” Sociological Methods \& Research 37 (4): 531-59. doi:10.1177/0049124109335735.

World Bank Group. 2019. Poverty and Equity Brief: China. https://databank.worldbank.org/data/download/poverty/33EF03BB-9722-4AE2-ABC7AA2972D68AFE/Global_POVEQ_EAP.pdf

World Economic Forum. 2018. The Global Gender Gap Report 2018.

Xie, Yu, and Kimberlee A Shauman. 2003. Women in Science: Career Processes and Outcomes. Vol. 26. Cambridge, MA: Harvard University Press.

Xie, Yu, and Xiang Zhou. 2014. "Income Inequality in Today's China." Proceedings of the National Academy of Sciences of the United States of America 111 (19): 6928-33. doi:10.1073/pnas.1403158111.

Xiu, Lin, and Morley Gunderson. 2015. "Occupational Segregation and the Gender Earnings Gap in China: Devils in the Details.” International Journal of Manpower 36 (5): 711-32. doi:10.1108/IJM-03-2013-0047.

Xu, Duoduo, and Xiaogang Wu. 2016. Separate and Unequal: Hukou, School Segregation, and Migrant Children's Education in Urban China. 16-856. PSC Research Reports. Population Studies 
Center, University of Michigan Institute for Social Research.

Zhang, Yuping, and Emily Hannum. 2015. "Diverging Fortunes: The Evolution of Gender Wage Gaps for Singles, Couples, and Parents in China." Chinese Journal of Sociology 1 (1): 15-55.

Zhao, Qiran, Xiaohua Yu, Xiaobing Wang, and Thomas Glauben. 2014. "The Impact of Parental Migration on Children's School Performance in Rural China." China Economic Review 31 (December): 43-54. doi:10.1016/j.chieco.2014.07.013.

Zhou, Xueguang. 2000. "Economic Transformation and Income Inequality in Urban China: Evidence from Panel Data.” American Journal of Sociology 105 (4): 1135-74. doi:10.1086/210401. 
Table 1. Descriptive Statistics for Full Sample and By Gender

\begin{tabular}{|c|c|c|c|c|c|c|c|}
\hline \multirow[b]{2}{*}{ Variables } & \multicolumn{2}{|c|}{ Full } & \multicolumn{2}{|c|}{ Female } & \multicolumn{2}{|c|}{ Male } & \multirow[b]{2}{*}{$\begin{array}{c}\text { Test of } \\
\text { Mean } \\
\text { difference }\end{array}$} \\
\hline & $\begin{array}{l}\text { Mean or } \\
\text { Percentage }\end{array}$ & SD & $\begin{array}{l}\text { Mean or } \\
\text { Percentage }\end{array}$ & SD & $\begin{array}{l}\text { Mean or } \\
\text { Percentage }\end{array}$ & SD & \\
\hline $\begin{array}{l}\text { Aspiration in Science and } \\
\text { Engineering }\end{array}$ & $8.1 \%$ & - & $2.2 \%$ & - & $13.5 \%$ & - & $* * *$ \\
\hline $\begin{array}{l}\text { Endorsement of Gender- } \\
\text { Math Stereotype }\end{array}$ & $55.3 \%$ & - & $50.3 \%$ & - & $60.0 \%$ & - & $* * *$ \\
\hline $\begin{array}{l}\text { Instrumental Motivation to } \\
\text { Learn Math }\end{array}$ & 3.182 & 0.850 & 3.159 & 0.850 & 3.204 & 0.849 & $* * *$ \\
\hline Parental Education & 10.862 & 3.042 & 10.896 & 3.071 & 10.830 & 3.015 & $\mathrm{x}$ \\
\hline Study Desk & $78.3 \%$ & - & $79.4 \%$ & - & $77.3 \%$ & - & $* *$ \\
\hline Books & 3.165 & 1.205 & 3.225 & 1.210 & 3.110 & 1.197 & $* * *$ \\
\hline Internet & $60.3 \%$ & - & $60.8 \%$ & - & $59.8 \%$ & - & $\mathrm{x}$ \\
\hline Migrant & $17.5 \%$ & - & $17.0 \%$ & - & $18.0 \%$ & - & $\mathrm{x}$ \\
\hline Minority & $8.3 \%$ & - & $8.6 \%$ & - & $8.0 \%$ & - & $\mathrm{x}$ \\
\hline Rural & $54.9 \%$ & - & $54.5 \%$ & - & $55.2 \%$ & - & $\mathrm{x}$ \\
\hline Only Child & $44.0 \%$ & - & $39.8 \%$ & - & $47.7 \%$ & - & $* * *$ \\
\hline Living with Both Parents & $77.2 \%$ & - & $78.3 \%$ & - & $76.2 \%$ & - & $* *$ \\
\hline \multicolumn{8}{|l|}{$\begin{array}{l}\text { Individual-level Control } \\
\text { Variables }\end{array}$} \\
\hline Grade 9 & $50.3 \%$ & - & $50.5 \%$ & - & $50.1 \%$ & - & $\mathrm{x}$ \\
\hline Math Test Score & 70.242 & 9.837 & 70.856 & 9.481 & 69.082 & 10.096 & $* * *$ \\
\hline Chinese Test Score & 70.213 & 9.746 & 73.247 & 8.328 & 67.442 & 10.067 & $* * *$ \\
\hline English Test Score & 70.189 & 9.817 & 73.139 & 8.533 & 67.495 & 10.089 & $* * *$ \\
\hline Cognitive Test Score & 0.030 & 0.855 & 0.038 & 0.847 & 0.022 & 0.861 & $\mathrm{x}$ \\
\hline Hours Spent on Homework & 5.605 & 4.118 & 5.910 & 4.137 & 5.326 & 4.080 & $* * *$ \\
\hline $\mathrm{N}$ & 18032 & & 8858 & & 9174 & & \\
\hline
\end{tabular}

a. Two-tailed t-test. ${ }^{* * *} \mathrm{p}<0.01,{ }^{* *} \mathrm{p}<0.05,{ }^{*} \mathrm{p}<0.1, \mathrm{x}=$ no significant difference. 


\section{Table 2. Logistic Regression Models Predicting Student's Aspiration in Science and Engineering}

\begin{tabular}{|c|c|c|c|c|c|c|c|}
\hline & $\begin{array}{l}\text { (1) } \\
\text { Full }\end{array}$ & & $\begin{array}{c}(2) \\
\text { Female }\end{array}$ & & $\begin{array}{l}(3) \\
\text { Male }\end{array}$ & & $\begin{array}{c}\text { (4) } \\
\text { Test of } \\
\text { Difference }\end{array}$ \\
\hline Female & $0.128^{* * *}$ & $(0.011)$ & & & & & \\
\hline Parental Education & $1.047^{* * *}$ & $(0.013)$ & $1.105^{* *}$ & $(0.035)$ & $1.038^{* *}$ & $(0.014)$ & ** \\
\hline Study Desk & 0.921 & $(0.070)$ & 1.001 & $(0.236)$ & 0.917 & $(0.075)$ & $\mathrm{x}$ \\
\hline Books & $1.093^{* *}$ & $(0.031)$ & $1.156^{*}$ & $(0.080)$ & $1.084^{*}$ & $(0.034)$ & $\mathrm{x}$ \\
\hline Internet & $0.792^{* *}$ & $(0.063)$ & 0.721 & $(0.123)$ & $0.804^{*}$ & $(0.067)$ & $\mathrm{x}$ \\
\hline Migrant & 1.084 & $(0.105)$ & 1.003 & $(0.225)$ & 1.091 & $(0.115)$ & $\mathrm{x}$ \\
\hline Minority & 1.146 & $(0.121)$ & 1.247 & $(0.340)$ & 1.127 & $(0.116)$ & $\mathrm{x}$ \\
\hline Rural Hukou & 0.980 & $(0.064)$ & 1.207 & $(0.245)$ & 0.952 & $(0.073)$ & $\mathrm{x}$ \\
\hline Only Child & 0.875 & $(0.063)$ & 0.938 & $(0.170)$ & $0.853^{*}$ & $(0.063)$ & $\mathrm{x}$ \\
\hline Living with Both Parents & 0.955 & $(0.072)$ & 1.031 & $(0.187)$ & 0.946 & $(0.075)$ & $\mathrm{x}$ \\
\hline \multicolumn{8}{|l|}{$\begin{array}{l}\text { Individual-Level } \\
\text { Control Variables }\end{array}$} \\
\hline Grade 9 & $0.761^{* * *}$ & $(0.050)$ & 0.892 & $(0.144)$ & $0.744^{* * *}$ & $(0.051)$ & \\
\hline Math Test Score & $1.041^{* * *}$ & $(0.006)$ & $1.032^{* *}$ & $(0.012)$ & $1.042^{* * *}$ & $(0.006)$ & \\
\hline Chinese Test Score & 0.997 & $(0.004)$ & 0.999 & $(0.012)$ & 0.996 & $(0.004)$ & \\
\hline English Test Score & 1.006 & $(0.004)$ & 1.010 & $(0.016)$ & 1.006 & $(0.005)$ & \\
\hline Cognitive Test Score & $1.105^{*}$ & $(0.046)$ & $1.336^{*}$ & $(0.169)$ & 1.073 & $(0.049)$ & \\
\hline $\begin{array}{l}\text { Hours Spent On } \\
\text { Homework }\end{array}$ & 1.004 & $(0.008)$ & 1.002 & $(0.023)$ & 1.005 & $(0.008)$ & \\
\hline Observations & 18032 & & 8858 & & 9174 & & \\
\hline
\end{tabular}

Note: Reporting odds ratios. Standard errors in parentheses. ${ }^{*} p<0.05,{ }^{* *} p<0.01,{ }^{* * *} p<0.001$.

Column 1 shows results using the full sample; column 2 shows results using the female subsample; column 3 shows results using the male subsample. Column 4 shows whether the observed gender differences in estimated effects are statistically significant by adding interaction terms between each independent variable and gender into a heterogenous choice model; $x$ means no significant difference. Survey weights and robust clustered errors at the school level are used in all models. School-level control variables are included in all models but omitted from the table. 
Table 3. Ordered Logistic Regression Models Predicting

Student's Instrumental Motivation to Learn Math

\begin{tabular}{|c|c|c|c|c|c|c|c|}
\hline & $\begin{array}{l}\text { (1) } \\
\text { Full }\end{array}$ & & $\begin{array}{c}(2) \\
\text { Female }\end{array}$ & & $\begin{array}{l}(3) \\
\text { Male }\end{array}$ & & $\begin{array}{c}\text { (4) } \\
\text { Test of } \\
\text { Difference }\end{array}$ \\
\hline Female & $0.844^{* * *}$ & $(0.025)$ & & & & & \\
\hline Parental Education & 0.989 & $(0.006)$ & 0.984 & $(0.008)$ & 0.994 & $(0.009)$ & $* * *$ \\
\hline Study Desk & 1.037 & $(0.055)$ & 0.990 & $(0.084)$ & 1.072 & $(0.055)$ & $* *$ \\
\hline Books & $1.140^{* * *}$ & $(0.018)$ & $1.131^{* * *}$ & $(0.026)$ & $1.151^{* * *}$ & $(0.026)$ & $* *$ \\
\hline Internet & $0.803^{* * *}$ & $(0.033)$ & $0.799^{* * *}$ & $(0.043)$ & $0.810^{* * *}$ & $(0.041)$ & $* *$ \\
\hline Migrant & 0.991 & $(0.047)$ & 1.010 & $(0.067)$ & 0.972 & $(0.061)$ & $\mathrm{x}$ \\
\hline Minority & $1.240^{*}$ & $(0.125)$ & $1.408^{* *}$ & $(0.162)$ & 1.105 & $(0.108)$ & $* *$ \\
\hline Rural Hukou & $1.108^{* *}$ & $(0.042)$ & $1.122^{*}$ & $(0.062)$ & 1.097 & $(0.054)$ & $*$ \\
\hline Only Child & 0.996 & $(0.042)$ & 0.947 & $(0.054)$ & 1.044 & $(0.056)$ & $* * *$ \\
\hline Living with Both Parents & $1.087^{*}$ & $(0.037)$ & $1.152^{* *}$ & $(0.061)$ & 1.034 & $(0.049)$ & $\mathrm{x}$ \\
\hline \multicolumn{8}{|l|}{$\begin{array}{l}\text { Individual-Level } \\
\text { Control Variables }\end{array}$} \\
\hline Grade 9 & $0.452^{* * *}$ & $(0.027)$ & $0.443^{* * *}$ & $(0.033)$ & $0.460^{* * *}$ & $(0.029)$ & \\
\hline Math Test Score & $1.037^{* * *}$ & $(0.003)$ & $1.037^{* * *}$ & $(0.004)$ & $1.039^{* * *}$ & $(0.003)$ & \\
\hline Chinese Test Score & 1.003 & $(0.002)$ & 1.004 & $(0.004)$ & 1.003 & $(0.003)$ & \\
\hline English Test Score & $0.992^{* * *}$ & $(0.002)$ & $0.992^{*}$ & $(0.004)$ & $0.990^{* *}$ & $(0.003)$ & \\
\hline Cognitive Test Score & $1.085^{* *}$ & $(0.028)$ & 1.054 & $(0.035)$ & $1.115^{* * *}$ & $(0.035)$ & \\
\hline $\begin{array}{l}\text { Hours Spent On } \\
\text { Homework }\end{array}$ & 0.997 & $(0.005)$ & 0.991 & $(0.006)$ & 1.001 & $(0.006)$ & \\
\hline Observations & 18032 & & 8858 & & 9174 & & \\
\hline
\end{tabular}

Note: Reporting odds ratios. Standard errors in parentheses. ${ }^{*} p<0.05,{ }^{* *} p<0.01,{ }^{* * *} p<0.001$.

Column 1 shows results using the full sample; column 2 shows results using the female subsample; column 3 shows results using the male subsample. Column 4 shows whether the observed gender differences in estimated effects are statistically significant by adding interaction terms between each independent variable and gender into a heterogenous choice model; $x$ means no significant difference. Survey weights and robust clustered errors at the school level are used in all models. School-level control variables are included in all models but omitted from the table. 
Table 4. Logistic Regression Models Predicting Student's Endorsement of Gender-Math Stereotype

\begin{tabular}{|c|c|c|c|c|c|c|c|}
\hline & $\begin{array}{l}(1) \\
\text { Full }\end{array}$ & & $\begin{array}{c}(2) \\
\text { Female }\end{array}$ & & $\begin{array}{c}(3) \\
\text { Male }\end{array}$ & & $\begin{array}{c}\text { (4) } \\
\text { Test of } \\
\text { Difference }\end{array}$ \\
\hline Female & $0.650^{* * *}$ & $(0.030)$ & & & & & \\
\hline Parental Education & 0.989 & $(0.007)$ & $0.962^{* * *}$ & $(0.010)$ & 1.017 & $(0.009)$ & $* * *$ \\
\hline Study Desk & 1.077 & $(0.049)$ & 1.048 & $(0.068)$ & 1.102 & $(0.068)$ & $* * *$ \\
\hline Books & $0.962^{*}$ & $(0.017)$ & $0.935^{* *}$ & $(0.023)$ & 0.990 & $(0.023)$ & $* * *$ \\
\hline Internet & $1.093^{*}$ & $(0.044)$ & $1.184^{* *}$ & $(0.067)$ & 1.035 & $(0.056)$ & $\mathrm{x}$ \\
\hline Migrant & 1.042 & $(0.048)$ & 1.036 & $(0.075)$ & 1.043 & $(0.075)$ & $\mathrm{x}$ \\
\hline Minority & 1.138 & $(0.076)$ & 1.086 & $(0.131)$ & 1.100 & $(0.066)$ & $\mathrm{x}$ \\
\hline Rural Hukou & 1.012 & $(0.039)$ & 0.985 & $(0.051)$ & 1.010 & $(0.053)$ & $\mathrm{x}$ \\
\hline Only Child & 1.023 & $(0.040)$ & 1.010 & $(0.060)$ & 1.044 & $(0.053)$ & $* *$ \\
\hline Living with Both Parents & 0.972 & $(0.043)$ & 0.950 & $(0.064)$ & 1.009 & $(0.054)$ & $*$ \\
\hline \multicolumn{8}{|l|}{$\begin{array}{l}\text { Individual-Level } \\
\text { Control Variables }\end{array}$} \\
\hline Grade 9 & $1.276^{* * *}$ & $(0.078)$ & $1.666^{* * *}$ & $(0.111)$ & 0.992 & $(0.073)$ & \\
\hline Math Test Score & $0.994^{*}$ & $(0.002)$ & $0.949^{* * *}$ & $(0.003)$ & $1.033^{* * *}$ & $(0.004)$ & \\
\hline Chinese Test Score & 1.002 & $(0.003)$ & $1.018^{* * *}$ & $(0.004)$ & $0.989^{* * *}$ & $(0.003)$ & \\
\hline English Test Score & $1.006^{*}$ & $(0.003)$ & $1.025^{* * *}$ & $(0.004)$ & $0.991^{*}$ & $(0.004)$ & \\
\hline Cognitive Test Score & 1.001 & $(0.024)$ & $0.861^{* * *}$ & $(0.033)$ & $1.144^{* * *}$ & $(0.035)$ & \\
\hline $\begin{array}{l}\text { Hours Spent On } \\
\text { Homework }\end{array}$ & 1.007 & $(0.004)$ & $1.015^{*}$ & $(0.006)$ & 0.995 & $(0.006)$ & \\
\hline Observations & 18032 & & 8858 & & 9174 & & \\
\hline
\end{tabular}

Note: Reporting odds ratios. Standard errors in parentheses. ${ }^{*} p<0.05,{ }^{* *} p<0.01,{ }^{* * *} p<0.001$.

Column 1 shows results using the full sample; column 2 shows results using the female subsample; column 3 shows results using the male subsample. Column 4 shows whether the observed gender differences in estimated effects are statistically significant by adding interaction terms between each independent variable and gender into a heterogenous choice model; x means no significant difference. Survey weights and robust clustered errors at the school level are used in all models. School-level control variables are included in all models but omitted from the table. 